\title{
A ilegalidade do trabalho prisional: análise da legalidade da mercantilização da pobreza e a crítica à forma jurídica
}

The illegality of prison work: analysis of the legality of the marketing of poverty and the criticism to the legal form

Mariane Lima Borges Brasil ${ }^{1}$

Odara Gonzaga de Andrade ${ }^{2}$

RESUMO: Almeja-se abordar a contradição presente na legalidade e ilegalidade do trabalho prisional, tendo em vista que nos parâmetros constitucionais brasileiros tal exploração é inconstitucional. Além disso, demonstra-se que o não reconhecimento legal da relação de emprego nos moldes celetistas constitui, também, afronta direta ao princípio da igualdade jurídica. Ademais, evidencia-se que o crescente processo de mercantilização do labor prisional contribui em absoluto para a transformação de sujeitos de delito no Brasil, assim como em todos os países da periferia do capital. Ainda, critica-se a crescente

1 Mestranda em Direito do Trabalho e Seguridade Social pela Faculdade de Direito da Universidade de São Paulo (FD-USP). Integrante do Grupo de Pesquisa Trabalho e Capital (GPTC-USP) e do Núcleo de Estudos em Trabalho, História e Direitos Sociais (NETHDSUFLA). E-mail: mariane.brasil96@gmail.com/mariane.brasil@usp.br

2 Mestranda em Direito do Trabalho e Seguridade Social da faculdade de direito da USP, membra do grupo de estudos Direitos humanos, Centralidade do Trabalho e Marxismo (DHCTEM), pesquisadora no núcleo de Direito Global e Desenvolvimento da Fundação Getúlio Vargas. E-mail: odara.gonzaga@usp.br 
cultura punitivista visando a criminalização racial e à disciplina ao trabalho forçado de presas e presos. Espera-se, desse modo, sinalizar os impactos de tais mudanças na vida da classe trabalhadora e fomentar aprofundamento do estudo sobre o papel do direito no processo de obste à mercantilização e do labor humano.

PALAVRAS-CHAVE: Mão de Obra Encarcerada. Sujeitos de Direito. Mercantilização. CLT.

ABSTRACT: Illegality of prision work: an alalysis of the legality of poverty merchantability and legal criticism. It aims to address the contradiction present in the legality and illegality of prison work, considering that in Brazilian constitutional parameters such exploitation is unconstitutional. Moreover, it is shown that the non-legal recognition of the employment relationship in the Celetist manner is also a direct affront to the principle of legal equality. As well, it is evident that the increasing process of commercialization of prison labor contributes absolutely to the transformation of criminal subjects in Brazil, as in all countries on the periphery of the capital. Also criticizes the growing punitivist culture aimed at racial criminalization and discipline to forced labor of prisoners. It is hoped, thus, to signal the impacts of such changes on the working class life and to foster further study on the role of law in the process of barring mercantilization and human labor.

KEYWORDS: Incarcerated Labor. Subjects of Law ercantilization. CLT

\section{INTRODUÇÃO}

Levando em conta a crítica ao Direito, cunhada por Pachukanis (2017), deve-se ter em mente em como esta forma jurídica se universaliza no modo de produção capitalista. Assim sendo, ao analisar o que seria o direito e como o direito opera esta análise não pode concentrar nas normas por si só, mas na forma jurídica. Isso acontece porque, de acordo com o autor, em todas as tentativas de abordagem do conceito do direito este aparece como apenas um conjunto de normas. E, ainda que algumas teorias pretendam determinar o conteúdo 
material dessas normas jurídicas, estas ainda correm pela abstração e pela não historicidade, visto que não basta usar o materialismo para se determinar como se preenche uma norma. A essência do direito não é a norma (há normas em vários outros campos), o direito como norma pressupõe sujeito de direitos. Ou seja, destina-se à categoria de sujeitos por ele mesmo criada.

Diante dessa ideia, portanto, é preciso identificar os elementos da forma jurídica, são eles: sujeitos e ideologia. A forma jurídica atua, dessa maneira, para a categoria de sujeitos de direito por ela criada e interpela esta atuação por uma ideologia. Abrigando, assim, os aspectos de neutralidade, universalidade e abstração numa operação quase que singela e não perceptível a olho nu. É somente no momento do capitalismo que certas relações sociais apresentam como forma abstrata, típica do direito.

Dada toda essa operação, o presente trabalho tem como finalidade abordar o trabalho prisional como cúmplice na marginalização de certos sujeitos de direitos, tornando-os, sujeitos de direitos proprietários de uma força de trabalho marginalizada e explorada de modo específico. Situando-Ihes não como sujeitos de direitos quaisquer, mas um sujeito de direito que se compõe, às vistas do ideário popular, como sujeito de delito.

Nesse contexto, é proposto uma investida específica quanto ao trato da marginalização e superexploração de suas forças de trabalho, em especial de jovens negras e negros, bem como demonstrar que a privatização dos presídios reforça tal estereótipo. Além de que sustentar que a inferiorizarão do trabalho encarcerado frente ao reconhecimento da relação de emprego passível de adequação à Consolidação das Leis do Trabalho (CLT) auxilia tal processo exploratório, assim como demonstrar que o trabalho prisional é inconstitucional diante de uma abordagem legal, para além de seu caráter imoral. À fim de habilitar os leitores a traçarem paralelos sociais, políticos, legais, de modo que se compreenda como a linguagem jurídica disfarça todo processo exploratório e intensifica o conflito de classes. 
Assim, serão abordadas, na medida do possível, as peculiaridades e as reconfigurações da mão de obra encarcerada na sociedade brasileira, sobretudo, a partir do conceito de forma jurídica supramencionada, idealizado nos estudos de Pachukanis. Para tanto, busca-se aporte teórico em levantamentos estatísticos, os quais indicam uma análise precisa sobre a constituição e os componentes populacionais no sistema carcerário.

Paralelamente, será dado um destaque à ideia de sujeitos de direitos e ideologia jurídica. Bem como a ideia de aparelhos repressivos de Estado, conduzida por Althusser, tendo em vista que esta atuação carcerária é cunhada, também, pelo poder político estatal que se mostra como um poder pertencente a classe dominante e seus aparelhos são imprescindíveis para compreensão do sistema prisional.

Dessa maneira, levando em conta que o crescente processo de mercantilização do labor prisional que contribui em absoluto para a transformação de sujeitos de delito no Brasil, assim como em todos os países da periferia do capital, e crescente cultura punitivista visando a criminalização racial e à disciplina ao trabalho forçado de presas e presos, esperamos poder evidenciar tais questões, sinalizar os impactos de tais mudanças na vida da classe trabalhadora e fomentar futuro aprofundamento do estudo sobre o papel do direito no processo de obste à mercantilização e do labor humano.

\section{A FORMA JURÍDICA PACHUKANIANA: SUJEITOS DE DIREITOS VERSUS SUJEITOS DE DELITO}

Na tentativa de compreender o trabalho prisional e como ele se faz fundamental à manutenção de um status quo de legalidade da mercantilização da pobreza e do crime, a presente análise parte do método materialista-histórico dialético e do estudo do direito por intermédio deste, utilizando os fundamentos analíticos da teoria geral do direito de Pachukanis (2017).

De antemão, importa buscar uma definição para a metodologia materialista histórica: em linhas gerais, o materialismo se opõe 
ao pensamento burguês fundado no idealismo do conhecimento. A partir dessa perspectiva, infere-se que o processo de desenvolvimento da realidade ocorre de maneira diversa do processo de conhecimento da realidade. O objetivo, portanto, gira em torno de compreender o concreto através do seu próprio desenvolvimento (BATISTA, 2013). Localiza-se o objeto na história e, em seguida, busca-se entender quais determinações ofuscam sua essência real para as relações sociais de produção.

Com a finalidade de compreender o direito e dele excluir as falsas determinações da realidade, Pachukanis inicia seus estudos sobre o direito da mesma maneira que Marx iniciou seus estudos críticos sobre a economia política: pela forma mais abstrata.

\begin{abstract}
E assim, do mesmo modo que Marx pôde identificar na forma da mercadoria o elemento mais simples pelo qual iniciar sua análise, também Pachukanis identificou na forma do sujeito esse elemento primário, irredutível, esse "átomo da teoria jurídica" e de cujos movimentos e articulações vai depender a possibilidade de uma compreensão materialista, isto é, científica, do elemento jurídico. (NAVES, 2017 in PACHUKANIS, 2017, p. 198).
\end{abstract}

Por essa linha de interpretação, com o intuito de delimitar o que há de específico no direito, Pachukanis chegará à conclusão de que a especificidade deste não está na normatividade, mas na sua forma jurídica, a qual possui como elementos o sujeito de direito e a ideologia jurídica. É a forma jurídica que cria a categoria dos sujeitos de direito, na qual todos e todas se colocam como proprietários e proprietárias ainda que de sua própria força de trabalho - livres e iguais no que se refere à circulação de mercadorias (PACHUKANIS, 2017).

Partindo desse pressuposto, o autor soviético, ao longo de sua obra, demonstra como o direito é específico do modo de produção capitalista, tendo em vista sua funcionalidade para a manutenção desse sistema. De um lado, a forma jurídica neutraliza a circulação de mercadorias, remetendo à ideia de que todos os sujeitos de direito são iguais e livres. De outro, ela universaliza o sistema de circulação de mercadorias por meio da extração do mais-valor avindo da exploração 
do trabalho. Demonstra-se, pois, que a realidade social assume uma construção ideológica que tem como fundamento a forma jurídica.

Equivoca-se, então, quem parte da chave de que a crítica marxista do direito pretende comprovar uma ideia segundo a qual o direito seria uma forma conscientemente manipulada pela burguesia contra a classe trabalhadora. Em verdade, a crítica marxista do direito pretende desmistificar as categorias do direito e localizá-las no modo de produção, a fim de compreender a funcionalidade primeiro (direito) em relação a este (modo de produção).

No que se refere à forma-sujeito do direito, importa destacar que ela não serve apenas à circulação de mercadorias, mas sim para circular uma mercadora historicamente determinada: a força de trabalho. O modo de organização necessário para tal consiste na interpelação de uma ideologia que cria os sujeitos de direito. Novamente, reforça-se que a figura dos sujeitos atrelada à ideologia jurídica disfarça o processo da circulação, visto que se coloca como categoria abstrata e neutra, regida sob os pilares da igualdade e da liberdade no seio da sociedade capitalista.

Em estudo acerca do processo penal e da mercantilização da pobreza, faz-se indispensável o entendimento do papel do Estado na operação. Nesse sentido, partindo das concepções de que (i) é a ideologia que interpela os indivíduos como sujeitos (de direito); e (ii) o que se representa na ideologia é a representação imaginária desses indivíduos com as relações reais em que vivem (ALTHUSSER, 1996, p. 128-131), o Estado se coloca, para além do "Estado antes de tudo é um aparelho de Estado", como sistema de reconhecimento e de garantia universal da condição de sujeito de direito. Isso se dá por intermédio da neutralização necessária à abstração das categorias jurídicas, que funciona em prol da perpetuação de seus aparelhos ideológicos e repressivos (ALTHUSSER, 1996). Tais aparelhos são funcionais para a manutenção da estrutura de poder no capitalismo. Acrescenta-se, ainda, a afirmação de Pachukanis (2007), em referência a Hauriou, de que o Estado burguês tem a capacidade de harmonizar forças e poderes para assegurar a "paz social".

Dado esse contexto, ao evocar Althusser (1996), percebe-se que a ideologia garante, simultaneamente, quatro aspectos: (i) interpelação 
dos indivíduos como sujeitos; (ii) sujeição destes sujeitos a um Sujeito ${ }^{3}$ (supra); (iii) reconhecimento mútuo entre os sujeitos e o Sujeito, reconhecimento entre os sujeitos e o reconhecimento de si mesmo pelo sujeito; e (iv) garantia absoluta de que tudo é como é, desde que os sujeitos reconheçam o que se são e se comportem como tal - ou seja, desde que haja garantia de ordem pela sujeição. Essas quatro relações fundamentam a relação entre os aparelhos do Estados, aparelhos estes que constituem a base para a existência da entidade estatal.

Não obstante, tem-se que o Estado possui aparelhos repressivos e ideológicos. Os primeiros funcionam predominantemente pela repressão e secundariamente pela ideologia. Os últimos, por sua vez, funcionam pela ideológica que se estabelece como relação imaginária entre indivíduos com as relações reais por ele vividas (ALTHUSSER, 1996, p. 124-128). No mais, a relação entre os aparelhos do Estado se dá pela interpelação quádrupla entre os sujeitos: garante a submissão e reconhecimento ao Sujeito (Estado), por meio dos aparelhos ideológicos (AIE) que, vez ou outra, precisão se utilizar seus aparelhos repressivos (ARE) em nome da garantia da estabilidade necessária à circulação de mercadorias.

Sendo assim, ao pensar no sistema prisional, o primeiro impulso é pensá-lo enquanto manifestação primária do aparelho repressivo do Estado. No entanto, não seria ocioso lembrar que a noção de furto foi definida antes da noção de propriedade. Dada essa contradição, é necessário compreender a especificidade do modo de produção capitalista. Para cumprir tal tarefa, abordar-se-á, a seguir, a noção pachikaniana desta relação, tentando adquirir aporte que substancie o fenômeno da mercantilização da pobreza.

\subsection{OS SUJEITOS DE DELITO}

Pachukanis (2017) afirma que do mesmo modo que o direito privado reflete de modo mais imediato as condições mais gerais de existência

3 O autor faz uma análise a partir da metáfora da figura da divindade para a religião e a relação entre os fiéis e esta divindade. 
da norma jurídica como tal, o direito penal é o campo no qual este intercâmbio jurídica alcança sua máxima tensão. $\mathrm{O}$ autor destaca ainda que

No processo judicial surge, de modo particularmente claro, a transformação das ações de um homem concreto em ação de uma parte, ou seja, de um sujeito jurídico. Para frisar a diferença das ações cotidianas e corriqueiras e das manifestações da vontade em relação às manifestações de vontade jurídicas, o direito antigo utilizava fórmulas e rituais solenes particulares (PACHUKANIS, 2017, p. 200).

Nesse contexto, o autor esclarece que a origem do Código Penal se relaciona ao costume da vingança de sangue. Esta se transformou em punição - pela Lei do Talião - ao mesmo tempo em que ganhava forças o sistema de composição ou de resgate em dinheiro. Atrela-se, então, a ideia do equivalente cuja forma é a mesma da forma mercadoria. Diante disso, Pachukanis (2017) estabelece que "o crime pode ser entendido como uma variedade particular de circulação, na qual a relação de troca, ou seja, contratual, é estabelecida post factum, ou seja, depois da ação voluntária de uma das partes" (PACHUKANIS, 2017, p. 202). Infere-se, assim, uma ideia de equivaler o prejuízo sofrido pela vítima.

Essa construção jurídica do equivalente se realiza, objetivamente, apenas no grau de desenvolvimento econômico em que essa forma - de equivalência - torna-se costumeira como equiparação na troca. Nesse contexto, a vingança, enquanto fenômeno biológico, transforma-se em instituto jurídico, na medida em que se entrelaça à troca de valor, relacionada à aludida ideia do equivalente (PACHUKANIS, 2017, p. 203).

É possível observar que a sociedade burguesa sustenta sua dominação a partir não apenas da exploração da classe proletária, mas também da sua submissão aos aparelhos repressivos do Estado. Afinal, "a jurisdição penal do Estado burguês é o terror de classe organizado, que difere apenas em grau das assim chamadas medidas de exceção, empregadas em momentos de guerra civil" (PACHUKANIS, 2017, p. 207). 
O direito penal, como parte da estrutura jurídica, assume a forma da troca de equivalentes. Coloca-se, portanto, como umas faces do Estado; este compreendido como o ente necessário para a correlação entre os produtores de mercadorias independentes e iguais que se confrontam no mercado (PACHUKANIS, 2017). O tribunal penal, por essa ótica, para além da forma abstrata do direito, constitui-se como um instrumento de luta de classes direto: quanto mais tensa a luta, mais difícil a dominação de classe. O tribunal é um julgador parcial, "ocupado pela organização da imediata justiça sumária de classe, que, em seus atos, guia-se apenas por considerações de utilidade política" (PACHUKANIS, 2017, p. 210).

Levando em conta a interpretação pachukaniana sobre o direito penal, percebe-se que este não se equivale ao prejuízo da vítima, mas à transgressão da norma estabelecida pelo Estado (a vítima se torna um pano de fundo em que a ação judicial se desenrola). Há uma abstração do interesse público que se apoia na figura da vítima:

Essa bipartição, sob a qual esse mesmo poder do Estado atua tanto no papel de parte (promotor público), como no papel de juiz, mostra que o processo penal, como forma jurídica, é inseparável da figura da vítima que exige uma "recompensa" e, por conseguinte, é inseparável da forma mais geral do contrato (PACHUKANIS, 2017, p. 211).

No procedimento penal-judiciário moderno, diferentemente do direito penal arcaico (ao qual apenas interessava o conceito de dano), o conceito de responsabilidade vem atrelado ao individualismo da pena. A responsabilidade surge como um ajuste de contas. "O criminoso responde com sua liberdade pelo crime e responde com o quinhão de liberdade que é proporcional à gravidade daquilo que fez" (PACHUKANIS, 2017, p. 214). Não obstante, destaca-se o que o autor soviético afirma sobre as garantias penais:

Não lhe resta nada mais do que fazer com que o delinquente pague com moeda miúda (tantas e tantas semanas de privação de liberdade) por um crime miúdo. No mais, a justiça burguesa toma 
todos os cuidados para que o contrato com o delinquente seja selado conforme todas as regras da arte, ou seja, de modo que cada um possa certificar-se e verificar que o pagamento foi fixado conforme a justiça (a publicidade do processo judicial), que o delinquente possa negociar livremente (o contraditório do processo), que ele, ademais, possa utilizar os serviços de um representante judicial experiente (direito de defesa) etc. Resumindo, o Estado enquadra sua relação com o delinquente nos limites de uma relação de troca escrupulosa, e nisso consistem as assim chamadas garantias processuais penais (PACHUKANIS, 2017, p. 218).

Por todo o exposto, é possível inferir que o direito penal, como parte da superestrutura da forma jurídica e se valendo da noção dos equivalentes, depende também das noções de contrato. Pautado pela responsabilidade individualizada, a troca de equivalentes pelo dano - ao interesse público em geral - necessita de sujeitos. Aqui, então, parte-se da ideia de que estes sujeitos, além da noção de sujeitos de direito, são sujeitos de delito.

$\mathrm{Na}$ noção de sujeitos de direito do delito estão abarcados aqueles e aquelas que, por sua condição marginal de vida - no modo de produção capitalista - ocupam uma parte invisibilizada pelo direito. Essa invisibilidade os impede de alcançar a ideia de sujeitos de direitos com direitos, ou seja, de sujeitos de direito portadores das garantias jurídicas. Na concretude dos fatos, são sujeitos de direito do delito, vez que sua condição de sujeito de direito está condicionada à equivalência do processo penal. São capturados pelo Estado pela criminalização criada para exclusão.

Nesse sentido, tem-se aqui um dos grupos mais vulneráveis da sociedade. Grupo de pessoas que são colocadas em exclusão para precarização do trabalho e da manutenção da exploração pela força de trabalho. Grupo criminalizado pela métrica burguesa do crime, pelos tribunais neutros que pretendem a neutralização da luta de classes. Em outras palavras, são criminalizados por serem sujeitos de delito. $O$ equivalente é pago pela liberdade e pelo trabalho.

Essa lógica é contraditória até pela forma jurídica, em que os sujeitos são proprietários nem que seja da própria força de trabalho. 
Aqui, os sujeitos são equivalentes do delito. Dessa maneira, o intuito é demonstrar como essa lógica de criação dos sujeitos de direito do delito é oposta à própria forma jurídica, trazendo aportes para defesa do sistema constitucional como tático para manutenção da sobrevivência das trabalhadoras e os trabalhadores no capitalismo. O que se pretendeu com a apresentação da teoria crítica do Direito de Pachukanis foi fornecer o arcabouço inicial para uma crítica do direito enquanto aparência para universalização do capitalismo. Embora tal crítica seja necessária, é preciso pensar na sua manutenção estratégica com fim de superação. Assim, pelo restante do trabalho, a ideia de salvaguardar a garantia de direitos destes sujeitos de direito do delito corrobora com esta postura. A luta, portanto, não é pelo direito à dignidade, mas pela dignidade.

\section{A PRIVATIZAÇÃO DE PRESÍDIOS E A MERCANTILIZAÇÃO DO CRIME E DA POBREZA}

Para a melhor compreensão dos objetivos deste trabalho, imperioso delimitar o que se chama aqui de privatização dos presídios. Partindo da definição de privatização lato sensu, tem-se que:

(...) O ponto característico nuclear desses regimes consiste em que a parceria do Estado é formalizada junto com pessoas de direito privado e da iniciativa privada, ou seja, aquelas que, reguladas pelo direito privado, não sofrem ingerência estatal em sua estrutura orgânica. A elas incumbirá a execução de serviços e atividades que beneficiem a coletividade, de modo que tal atuação se revestirá da qualificação de função delegada do Poder Público". (FILHO, 2013, p. 432-433)

A privatização de presídios parte da lógica neoliberal, incitada pelo contexto de globalização econômica e do modelo de produção vigente (capitalista), os quais visam à diminuição do aparelhamento do Estado, sob o pretexto de "modernização" e contenção de gastos frente às crises do Capital. Passam, então, a defender e executar os serviços públicos através do regime de parceria, caracterizados pela aliança entre 
o Poder Público e entidades privadas, por meio de uma delegação negocial, isto é, delegando ao agente privado, através de negociações, à execução de serviços públicos (FILHO, 2013). Em contrapartida, o particular recebe o influxo de normas de direito público, uma vez que tem como finalidade a prestação de serviços públicos do próprio Estado (MATOS, 2017). Em síntese:

Os negócios jurídicos que materializam a delegação negocial são as concessões e as permissões de serviços públicos, que possuem expressa previsão constitucional (art. 175). As concessões especiais são caracterizadas pela contraprestação pecuniária recebida pelo concessionário e se subdividem em patrocinadas e administrativas. Há, ainda, a concessão especial de serviços públicos, também chamada de parceria público-privada, regulada pela Lei 11.079/2004. Na modalidade patrocinada, o concessionário recebe recursos financeiros tanto da tarifa cobrada dos usuários do serviço prestado quanto de uma contraprestação pecuniária devida pelo Poder Público. Na concessão administrativa, a Administração Pública é sua usuária direta ou indireta, não comportando remuneração de tarifas pelos usuários, mas apenas pagamento direto do concedente (MATOS, 2017, p. 7).

A modalidade da concessão especial de serviços público, isto é, a parceria público-privada (Lei 11,079/2004) é a utilizada no contexto prisional-privatista brasileiro e a aqui contestada. Não se faz ocioso descrever as principais características da modalidade parceria público-privada, quais sejam: o financiamento do setor privado, o compartilhamento de riscos e a pluralidade compensatória (FILHO, 2013). Isto é, o Poder Público não disponibilizará integralmente recursos financeiros para os empreendimentos que contratar; apenas se solidarizará com o ente privado no caso de eventuais prejuízos ou déficit; e terá obrigação em favor do concessionário pela execução da obra ou do serviço, admitindo contraprestação pecuniária de espécies diversas (FILHO, 2013).

Desse modo, a partir dessas breves definições, entende-se como privatização a parceria entre o setor público e o setor privado, a qual 
envolve a construção de obras públicas na modalidade de concessão administrativa, serviços de fornecimento e, também, os de execução e administração (MATOS, 2017). Adotada essa definição, analisa-se a privatização do sistema prisional brasileiro, sujas justificativas, causa e consequência. Tal modelo e proposta prisional se baseiam em argumentos quanto ao estado de medievalidade das prisões, de superlotação, violação de direitos humanos fundamentais, da cultura da punição. Assim, a ideologia neoliberal travestida parte logo para o pragmatismo, assegurando que a solução é justamente a redução do Estado e a descentralização do poder administrativo, com a necessária privatização dos presídios. Mas, como bem explica Erica Matos:

As políticas criminais, no entanto, costumam se pautar no imediatismo e no populismo penal, sem levar em conta políticas públicas sociais necessárias para desestruturar certas determinações do crime. Assim, em detrimento de políticas de educação, saúde, emprego, moradia, entre outras, a política criminal brasileira se orienta, sobretudo, na reforma de leis mais duras e policiamento ostensivo, em resposta ao clamor popular, e construção de novos presídios, com o fim de encobertar problemas visíveis causados pela superpopulação. (MATOS, 2017, p. 8).

Nesse diagrama, questionamentos sobre a proteção jurídica foram colocados em xeque e foi trazido à baila o movimento de defesa de privatizações do cárcere, sob os argumentos de livre concorrência, redução de custos, otimização do gerenciamento, entre outros. Dentro da lógica de acumulação de capital, percebe-se que os critérios e objetivos sociais são substituídos por preceitos mercantis (MATOS, 2017). Nessa linha,

Tal proposta [de privatização] se assegura principalmente em premissas economicistas da crise do sistema carcerário, concebida em termos físicos e monetários. A privatização do sistema levaria a custos menores, serviços de melhor qualidade e aumento no nível de responsabilização. Isso porque as empresas privadas teriam mais interesse que o Governo em evitar faIhas, já que essas contribuiriam para uma propaganda negativa. 
Além disso, a competição do meio privado levaria à otimização dos serviços com baixo custo. Soma-se a isso o fato de que o Estado, supostamente, possui altos custos operacionais, além de estar sujeito a práticas corruptoras do processo político. Em contrapartida, empresas privadas estão sujeitas a um contrato, que podem apresentar padrões de desempenho e sanções em caso de não cumprimento. (MINHOTO, 2000, p. 67).

Ocorre que, além do fato das propostas se basearem em concepções e leituras bastante singulares da criminalidade e da sua própria conexão com a prisão, a defesa da privatização do cárcere despreza por completo os problemas estruturais dessa nova gestão da violência, reforçando e legitimando o (falho) papel da pena privativa de liberdade, bem como reforçando a crença da população na funcionalidade do sistema penal (MATOS, 2017). Entende-se, nessa linha, o cárcere como solução primeira, ignorando a função última ratio, isto é, a sua excepcionalidade. A partir dessa perspectiva, passa-se a acreditar que a ineficiência administrativa do Estado é o único problema a ser combatido. "Isso porque se desconsideram totalmente os papéis da instituição de gestão da população pobre e negra e de manutenção da estratificação social e racial, baseados na lógica de encarceramento em massa seletivo" (MATOS, 2017, p. 8).

Frente a essa visão limitada, o ponto determinante a ser debruçado parte de uma análise legal, cuja conclusão é pela inconstitucionalidade da delegação do poder punitivo do Estado ao setor privado. À luz da Constituição Federal, em particular do art. $5^{\circ}$, incisos XXXVII e LIII, juízos e tribunais de exceção são terminantemente proibidos, de tal forma que somente a autoridade competente é capaz de processar e sentenciar um cidadão. Assim, uma instituição privada jamais estaria apta para fazer uso da força e da coação na sua administração, assim como para julgar as infrações graves ou decidir a respeito de regime disciplinar diferenciado, funções atribuídas ao juiz da execução pela Lei de Execução Penal (MATOS, 2017). Ademais, a imposição do domínio de um particular em relação ao outro, colocando um em posição tão superior aos demais, constitui ofensa direta ao princípio da igualdade expresso no art. $5^{\circ}$ da Carta Constitucional. Sendo assim, 
defende-se a execução da pena como função pública intransferível, de forma que destituir o monopólio do direito de punir do Estado e repassá-lo a particulares é inconstitucional (MATOS, 2017).

Em verdade, o período de execução da pena privativa de liberdade, por si só, já representa uma violação imensa ao condenado (MATOS, 2017). "Como, portanto, esperar que uma instituição privada a tenha consciência disso? Ainda mais inconveniente indagar: como é possível, do ponto de vista ético, auferir-se lucro do sofrimento alheio?" (MATOS, 2017, p. 9). Diminuir compreensões tão complexas a uma simples lógica mercantilista de custo-benefício é imoral e desumano. Uma questão que deveria ser tratada e estudada com emergência, devido a seu caráter de direitos humanos e sociais, converte-se em discussão puramente mercantil. Nesse ínterim,

Por meio da lógica das relações mercantis, pelos critérios de rentabilidade e de acumulação, o cárcere se torna um grande negócio, em que seu escopo central passa a ser a extração de lucro em detrimento dos interesses sociais. Nesse processo, os presos deixam de ser titulares de um direito social, transformando-se em meros consumidores de um serviço empresarial, reduzidos ao conceito geral de mercadoria. Soma-se a isso o fato de que, na prática, os argumentos defensivos tendem a não ser verídicos e os estabelecimentos privados tendem a reproduzir distorções dos estabelecimentos públicos (MATOS, 2017, p. 9).

Sob o mote de redução de custos, outras problemáticas emergem: uma vez que o objetivo maior das empresas é o lucro, há a restrição de gastos, o que leva à queda na qualidade dos serviços prestados e no nível de proteção e de segurança. "A desburocratização abre espaço para a contratação de funcionários pouco preparados, o que, por sua vez, aumenta a possibilidade de conflitos entre agentes e detentos" (MATOS, 2017, p. 9). Paulo Nicoli destaca, ainda, outra faceta:

Um outro supostamente forte argumento pró-privatizações, o da promessa de redução da superpopulação carcerária e dos níveis de reincidência, não se concretizou nos estabelecimentos prisionais privatizados norte-americanos, fato que o deixou ain- 
da mais vulnerável. A lógica capitalista de exploração máxima alia-se a tal frustração para iluminar uma possível razão oclusa. Seria, no mínimo, inocente supor-se que uma atividade privada de caráter industrial renderá esforços pela diminuição ou perda de seu objeto. (NICOLI, 2009, p. 6)

Igualmente questionável é a afirmação de que prisões administradas pelo setor privado possuem melhor desempenho. "Uma longa lista de práticas gerenciais ineptas pode ser detectada na experiência correcional privada estadunidense, englobando violência de funcionários contra detentos, corrupção, presença de drogas nos estabelecimentos e fugas reiteradas" (MINHOTO, 2009, p. 75). No mais, o avanço tecnológico contribuiu para que o cárcere se torne um bom negócio, visto que há o investimento maciço em mecanismos tecnológicos de segurança, como alarmes, redes elétricas, portões eletrônicos, agências de segurança, controle dos cárceres por satélite, tornozeleiras eletrônicas etc. Em síntese:

A defesa da implementação de prisões privadas é sustentada, sobretudo, por argumentos econômicos: enquanto o Estado precisa arcar com os contratos e concursos públicos, custos burocráticos, licitações e outros, as empresas privadas conseguiriam construir novas instituições de forma mais econômica e rápida. Além disso, está a concepção de que o livre mercado e a livre concorrência do setor privado levariam a serviços prisionais de melhor qualidade. Há, ainda, o argumento de que os contratos entre o Estado e as empresas privadas podem conter exigências e determinações que não se aplicam às prisões públicas, podendo, inclusive, ser rescindidos em casos de má gerência. Em contrapartida a tais argumentos, surgem críticas nos âmbitos legal, ético e moral. Os opositores à prática sustentam, em linhas gerais, ser inconstitucional a delegação do poder punitivo do Estado ao setor privado; ser antiético uma empresa privada lucrar com o sofrimento alheio; e, por fim, ser imoral a privatização das prisões, uma vez que tal prática privilegia o lucro em detrimento dos interesses e do bem-estar dos reclusos (MATOS, 2017, p. 3). 
Frente ao exposto, evidente que os interesses empresariais passam a ser os prioritários frente aos processos político-criminais, o que pode minar a implementação de políticas mais progressistas de combate ao encarceramento em massa. A consequência disso está na criminalização da pobreza e na desumanização ainda mais intensa do cárcere. Instaura-se, assim, a gestão da violência capitalista sob o mote da lógica de acumulação de capital em detrimento do social.

Do supracitado relatório do DEPEN, depreende-se que a maioria das pessoas privadas de liberdade no Brasil é jovem e negra: $56 \%$ da população carcerária tem entre 18 e 29 anos e $67 \%$ é negra, ao passo que apenas $31 \%$ é branca (INFOPEN, 2014, p. 140). Em um país onde a população é composta de $51 \%$ de negros e $48 \%$ de brancos, tal expressivo índice racial deve ser considerado. Acrescenta-se ainda que o grau de escolaridade das pessoas reclusas é extremamente baixo: apenas $07 \%$ chegaram a terminar o Ensino Médio (em contraste com $32 \%$ da população brasileira), sendo que $11 \%$ possuem esse grau de incompleto. Mais da metade dos presos sequer terminou o Ensino Fundamental (53\%), 9\% são alfabetizados sem cursos regulares e 6\% são analfabetos (MATOS, 2017, p. 4).

Apesar de não existirem fontes indicativas do perfil carcerário no que tange à renda, o que se conclui logicamente de tais dados é que quem lota as prisões brasileiras são, sobretudo, jovens negros e pertencentes à classe social baixa que sequer tem acesso à educação. Extrai-se, portanto, a "definição corrente da criminalidade como um fenômeno concentrado, principalmente, nos estratos inferiores, e pouco representada nos estratos superiores e, portanto, ligada a fatores pessoais e sociais correlacionados à pobreza" (MATOS, 2017, p. 4).

Diante do cenário caótico apresentado, tem-se que o debate sobre o encarceramento em massa, a seletividade racial e social do sistema, a descriminalização de condutas e outras políticas progressistas são esquecidas. Em detrimento desses assuntos, a prioridade recai sobre "pautas conservadoras, como diminuição da maioridade penal, criminalização de novas condutas, enrijecimento de penas e tudo aquilo que possa aumentar ainda mais a população carcerária, de forma a garantir o lucro das empresas envolvidas" (MATOS, 2017, p. 9). 
Resta claro que, na prática, a defesa das privatizações prisionais constitui meramente uma forma de dar lucratividade a empresas privadas, uma vez que não representam uma solução para os problemas relacionados ao sistema prisional como um todo. Pelo contrário, trata-se de agravante que dá origem a tantos novos inconvenientes.

Nesse sentido, diversas instituições comprometidas com a questão carcerária têm se posicionado contrariamente à privatização do sistema prisional. Recentemente, o Núcleo Especializado de Situação Carcerária da Defensoria Pública do Estado de São Paulo, a Pastoral Carcerária, o Instituto Terra Trabalho e Cidadania (ITTC) e o Instituto Brasileiro de Ciências Criminais (IBCCRIM) lançaram conjuntamente uma nota de repúdio Projeto de Lei 513/2011, que regulamenta a privatização do sistema carcerário. Alegam, em suma, a inconstitucionalidade da função punitiva do Estado para particulares e da privatização da assistência jurídica, além da superexploração do trabalho do preso (MATOS, 2017, p. 9).

O processo de privatização dos presídios simboliza um incontestável retrocesso no que diz respeito à política criminal, atuando na criminalização da pobreza e da população negra, respaldado em uma lógica de encarceramento, cujos alvos são negros, jovens e pobres. Além de ir de encontro com diversas questões morais e éticas, legitima a pena de prisão e desvia a atenção dos problemas estruturais do sistema, de forma que impossibilita a implementação de políticas públicas que, de fato, tenham poder de reverter tal cenário perverso.

Resta evidente, pois, que a privatização dos presídios representa a institucionalização da criminalização da pobreza, tendo como alvo a franja marginal da sociedade (negra), e visa apenas à mercantilização do crime e do labor precarizado dos encarcerados. Defendê-la significa ir contra os direitos humanos - frutos de lutas sociais, duramente conquistados - e de todas as formas de tratamento humano que seja verdadeiramente ressocializador, reeducador e promotor de reinserção social. 


\section{A INCONSTITUCIONALIDADE DO TRABALHO PRISIONAL E A NÃO SUBORDINAÇÃO À CONSOLIDAÇÃO DAS LEIS DO TRABALHO: ANÁLISE LEGAL}

O presente tópico tem como objeto o trabalho no cárcere, em particular o trabalho das pessoas que cumprem pena privativa de liberdade, especificamente no regime fechado e semiaberto. $O$ foco do estudo recai sobre a regulamentação legal desses regimes, pautados na obrigatoriedade do exercício do trabalho dentro dos presídios nos quais os presos estão definitivamente condenados (ou seja, não são presos preventivos). No mais, importa investigar a problemática relativa à não subordinação laboral dos trabalhadores encarcerados à Consolidação das Leis de Trabalho (CLT), com o efetivo reconhecimento da relação de emprego.

A título introdutório, cabe ressaltar que, no Brasil, o trabalho carcerário é regido principalmente pelas Regras Mínimas de Tratamento dos Reclusos da ONU, pela Lei de Execução Penal (LEP), pelo Código Penal e pela Constituição da Federal. Também, o trabalho prisional é inserido na legislação brasileira como um dever e como um direito do preso. Nesse sentido, o trabalho em si não é a pena, mas um acessório da pena que compõe o programa de individualização desta.

Ademais, todas as modalidades de pena no Brasil cumprem duas funções: retributiva e preventiva. A última possui a função de prevenção lato sensu, isto é, visa à sociedade e ao indivíduo delinquente. Este é neutralizado, retirado da sociedade. Ao mesmo tempo, representa a prevenção social positiva, composta na chamada "teoria re": ressocialização, reeducação e reinserção. O trabalho prisional aparece neste ponto da função da pena, e tem como um dos princípios norteadores a invidualização desta. Completando:

O trabalho no interior dos presídios aparece como discurso legitimante da função ressocializadora da pena. Por meio dele, o preso, para além da ocupação do tempo, teria condições de se qualificar, podendo ser reinserido no mercado de trabalho pos- 
teriormente, ser remunerado, além de ter o direito à remição de sua pena proporcionalmente aos dias trabalhados, nos termos do art. 126 da LEP. (MATOS, 2017, p. 10).

No que se refere a regulamentação do trabalho prisional, cabe ressaltar o disposto na Convenção n 29 de 1930 da Organização Internacional do Trabalho (OIT), que discorre sobre o trabalho forçado e obrigatório, fazendo uma exceção aos casos de trabalhos forçados prisionais, vejamos:

Art. 2 - 1. Para os fins da presente convenção, a expressão 'trabalho forçado ou obrigatório' designará todo trabalho ou serviço exigido de um indivíduo sob ameaça de qualquer penalidade e para o qual ele não se ofereceu de espontânea vontade.

2. Entretanto, a expressão 'trabalho forçado ou obrigatório' não compreenderá, para os fins da presente convenção:

(...) c) qualquer trabalho ou serviço exigido de um indivíduo como consequência de condenação pronunciada por decisão judiciária, contanto que esse trabalho ou serviço seja executado sob a fiscalização e o controle das autoridades públicas e que dito indivíduo não seja posto à disposição de particulares, companhias ou pessoas privadas (...) [grifo nosso].

Da leitura do dispositivo, extrai-se que a OIT, desde 1930, entende que o trabalho prisional se trata de uma modalidade de trabalho forçado, porém o excepciona para pessoas condenadas criminalmente pelo Judiciário. Tal fato é deveras curioso: a própria normativa da OIT excetua a função de cidadão das pessoas presas. Outro ponto em destaque dessa normativa é que somente o poder público pode fiscalizar e controlar o trabalho ou serviço prisional. No mais, fica claro que o indivíduo em questão não pode, de modo algum, ser posto à disposição de particulares, companhias ou pessoas privadas.

Posteriormente, em 1956, tem-se a Convenção da OIT n 105 , sobre a abolição do trabalho forçado. Esta amplia o entendimento acerca do trabalho forçado e obrigatório e inclui nessa modalidade trabalhos 
que são imposto a alguém como justificativa de disciplina do trabalho, isto é, os trabalhos prisionais. A doutrina majoritária justifica esse tratamento diferenciado aos presos em razão da questão da disciplina, afirmando ser esta inerente aos estabelecimentos prisionais. Contudo, como exposto, a própria OIT aduz que isso não pode ser justificativa para importar trabalho a ninguém. Na normativa, consta que:

Art. 1 - Qualquer Membro da Organização Internacional do Trabalho que ratifique a presente convenção se compromete a suprimir o trabalho forçado ou obrigatório, e a não recorrer ao mesmo sob forma alguma:

a) como medida de coerção, ou de educação política ou como sanção dirigida a pessoas que tenham ou exprimam certas opiniões políticas, ou manifestem sua oposição ideológica à ordem política, social ou econômica estabelecida;

b) como método de mobilização e de utilização da mão-de-obra para fins de desenvolvimento econômico;

c) como medida de disciplina de trabalho;

d) como punição por participação em greves;

e) como medida de discriminação racial, social, nacional ou religiosa [grifo nosso].

Ademais, ratificou a importância da abolição imediata e completa do trabalho forçado ou obrigatório.

Art. 2 - Qualquer Membro da Organização Internacional do Trabalho que ratifique a presente convenção se compromete a adotar medidas eficazes, no sentido da abolição imediata e completa do trabalho forçado ou obrigatório, tal como descrito no art. 1 da presente convenção.

Além disso, ainda na década de 50, a Convenção volta a elucidar a proibição da delegação de qualquer modalidade de trabalho forçado das autoridades competentes para particulares, em proveito destes. Isso significa que a ideia de privatização dos presídios brasileiros, bem como a exploração da mão de obra encarcerada por agentes privados, constitui explícita violação às normativas re- 
gidas pela OIT (e ratificadas por nosso país, salienta-se). Nas palavras exatas dos dispositivos em análise:

\begin{abstract}
Art. 4 - 1. As autoridades competentes não deverão impor ou deixar de impor o trabalho forçado ou obrigatório em proveito de particulares, de companhias, ou de pessoas jurídicas de direito privado.

Art. $5-1$. Nenhuma concessão feita a particulares, companhias ou pessoas jurídicas de direito privado deverá ter como consequência a imposição de qualquer forma de trabalho forçado ou obrigatório com o fim de produzir ou recolher os produtos que esses particulares, companhias ou pessoas jurídicas de direito privado utilizam ou negociam.
\end{abstract}

Há, ainda, dois outros tratados internacionais assinados pelo Brasil acerca da temática: o Pacto de Direitos Civis e Políticos da ONU e a Convenção Interamericana de Direitos Humanos. Estes seguem a mesma posição adotada pela convenção $n^{\circ} 29$ da OIT, isto é, assumem que o trabalho prisional é trabalho forçado e obrigatório, mas ilogicamente o excepcionam.

Nessa linha, o Pacto de São José da Costa Rica, ratificado pelo Brasil em 1992, inova ao prever expressamente em seu art. $6^{\circ}$ a proibição de trabalho forçado ou obrigatório por parte dos presos que cumprem pena privativa de liberdade. Logo, deixa claro que o trabalho do preso não se configura como forma de trabalho escravo ou degradante, exaltando a condição humana do preso e a necessidade de resguardar a sua dignidade. In verbis:

Artigo $6^{\circ}$ - Proibição da escravidão e da servidão:

1. Ninguém poderá ser submetido a escravidão ou servidão e tanto estas como o tráfico de escravos e o tráfico de mulheres são proibidos em todas as suas formas.

2. Ninguém deve ser constrangido a executar trabalho forçado ou obrigatório. Nos países em que se prescreve, para certos delitos, pena privativa de liberdade acompanhada de trabalhos forçados, esta disposição não pode ser interpretada no sentido de proibir o cumprimento da dita pena, imposta por um juiz ou 
tribunal competente. O trabalho forçado não deve afetar a dignidade, nem a capacidade física e intelectual do recluso.

3. Não constituem trabalhos forçados ou obrigatórios para os efeitos deste artigo:

4. Os trabalhos ou serviços normalmente exigidos de pessoa reclusa em cumprimento de sentença ou resolução formal expedida pela autoridade judiciária competente. Tais trabaIhos ou serviços devem ser executados sob a vigilância e controle das autoridades públicas, e os indivíduos que os executarem não devem ser postos à disposição de particulares, companhias ou pessoas jurídicas de caráter privado; (...) [grifo nosso].

No mais, a própria Constituição Federal de 1988 é clara ao proibir qualquer tipo de trabalho forçado e obrigatório, não fazendo exceção alguma. Ou seja, o proíbe-o em qualquer modalidade. Nos termos do art. $5^{\circ}$, XLVII, "não haverá penas: (...) c) de trabalhos forçados". Ademais, nosso Código Penal tipifica, no art. 149, o ato de submeter alguém a trabalho forçado:

A legislação brasileira, conquanto, diferencia o trabalhador livre do trabalhador preso, garantindo-Ihes direitos diferentes. A LEP prevê, em seu art. 31, a obrigatoriedade do trabalho de todos os presos, exceto aos presos provisórios. Tal dispositivo vai de encontro com a vedação de penas de trabalho forçado da Constituição Federal (art. 5 ${ }^{\circ}$ XLVII, c) e com a realidade dos presídios brasileiros, em que apenas $16 \%$ da sua população exerce atividade laborativa, conforme relatório do Infopen de 2014. (MATOS, 2017, p. 5)

A partir dessas considerações, em especial da análise da Lei de Execução Penal e do Código Penal, percebe-se que o trabalho não é apenas um direito, mas também um dever. Isso implica na impossibilidade de recusa de trabalho por parte do preso. De fato, tal situação gera uma série de punições a este, na medida em que, no regime de execução de penas, a conduta do preso é constantemente classificada como excelente, ótima, boa regular e ruim e, se 
o preso não possui boa conduta, fica impossibilitado de adquirir os benefícios da execução penal.

Nessa linha, o que se observa, na prática, é que se o preso se nega a trabalhar, tal atitude é encarada como falta grave, o que o impede de progredir de regime, de receber indulto, de ter direito à comutação da pena e ao livramento condicional, dentre outros benefícios. Disso depreende-se a existência de forte coação moral e social para que o preso trabalhe, não se apresentando como um direito, mas tão somente como um dever.

Outra contradição presente na Lei de Execução Penal (LEP) reside na obrigação, nos termos apontados, do trabalho prisional ao mesmo tempo que não concede tal possibilidade em diversos presídios. Segundo dados do INFOPEN (Levantamento Nacional de Informações Penitenciárias), menos de $15 \%$ dos presos estão trabalhando (INFOPEN, 2016, p. 56).

Como base legal, sabe-se que LEP é anterior à Constituição Federal de 1988. Pode-se afirmar, portanto, que a primeira não foi recepcionada pela ordem constitucional, vez que ficou proibido o trabalho forçado, sem qualquer menção a exceções. Assim, diante de tais problemas legais, a par das questões antiéticas e imorais em questão, conclui-se que a obrigatoriedade do trabalho prisional é contrária à própria Constituição.

Outro problema da Lei de Execução Penal se situa no não reconhecimento e não aplicação das normativas da Consolidação das Leis do Trabalho aos trabalhadores presos, não identificado a latente relação de emprego. Isso implica na (ainda) maior vulnerabilidade à exploração laboral dessas pessoas. Consequência desse fato está na afirmação de que o salário mínimo dos prisioneiros pode ser inferior ao mínimo constitucional, mais uma clara violação ao princípio da igualdade, constitucionalmente resguardado. Nessa linha, Erica Matos completa:

Assim, soa incoerente a definição da LEP de que o trabalho possui função educativa e produtiva, proporcionando a reinserção do condenado na sociedade, ao mesmo tempo que lhe confere tratamento desigual dos demais trabalhadores, permitindo o lucro 
das empresas privadas, por intermédio da máxima extração da mais-valia, retirando-lhe, inclusive, o direito constitucional de um salário mínimo, representando, portanto, verdadeira institucionalização de trabalho escravo (MATOS, 2017, p. 5).

Pois bem. O preso, ao trabalhar, enquadra-se em todas as características necessárias à constituição da relação de emprego. Ao excetuar sua situação apenas em razão de sua condição de presidiário ou presidiária (ou seja, de estar cumprindo pena privativa de liberdade), o que ocorre é uma clara ofensa à igualdade. Nesse ponto, vale ressaltar que a pena é privativa da liberdade, por excelência, e não de outros direitos. Por óbvio, tal restrição é acompanhada por outras, mas perder a possibilidade de exercício de um direito constitucional - o trabalho - e da livre escolha de laborar ou não ultrapassa os limites constitucionalmente impostos. Incorre-se, pois, em séria violação de direitos fundamentais da pessoa humana. Nesse sentido, a aludida autora aponta que:

Em seu art. 28, $\S 2^{\circ}$, a LEP dispõe, ainda, que o 'trabalho do preso não está sujeito ao regime da Consolidação das Leis do Trabalho'. Os direitos sociais garantidos ao trabalhador livre são assegurados ao trabalhador recluso, no limite da sua sentença e da lei. No entanto, se o recluso oferece sua mão de obra a uma empresa privada, em iguais condições de subordinação às quais os trabalhadores livres se subordinam, isso deveria ensejar um contrato com garantias e direitos idênticos aos demais empregados (MATOS, 2017 p. 5).

Parte da doutrina entende que a LEP, no que se refere aos direitos trabalhistas do preso, não foi recepcionada pela Constituição Federal de 1988, "posto que o novel diploma proíbe toda e qualquer discriminação entre os trabalhadores, como disposto em seu art. $7^{\circ}$, incisos XXXI e seguintes" (SOUZA, 2010, p. 20). Desta forma, leciona Aldacy Coutinho:

Se na prestação de trabalho pelo apenado estiverem presentes todos os elementos de uma relação de emprego, pela realização de um trabalho subordinado com continuidade e pessoalidade, 
o pagamento deverá ser igual ou superior a um salário mínimo. A norma constitucional, em seu art. $7^{\circ}$, inciso IV, garante a percepção de um salário mínimo por todo trabalhador. Sendo norma de eficácia plena, implica automaticamente a não recepção da Lei de Execução Penal, que permite a realização de trabalho remunerado pelo apenado em valores inferiores ao mínimo legal, quando está caracterizada a relação de emprego (COUTINHO, 1999, p. 7-20).

Ao não reconhecer a relação de emprego intrínseca ao trabalho prisional, faz-se com que o preso perca as garantias previstas na CLT. Além disso, ele deixa de gozar de direitos trabalhistas e de seguridade social ( $13^{\circ}$ salário, aposentadoria, FGTS, entre outros). Fica explícita, assim, a violação aos princípios da igualdade e da não discriminação. Ademais, não se deve esquecer que a Convenção $n^{\circ} 29$ da OIT assegura às pessoas que são forçadas e obrigadas a trabalhar, nas condições em que permite, os benefícios das legislações acidentárias de saúde e segurança advindas do trabalho, bem como de todas as legislações indenizatórias em vigor no território, aplicando a estas as mesmas condições recebidas pelos trabalhadores livres.

Art. $15-1$. Toda legislação concernente à indenização por acidentes ou moléstias resultantes de trabalho e toda legislação que prevê indenizações de pessoas dependentes de trabalhadores mortos ou inválidos, que estejam ou estiverem em vigor no território interessado, deverão se aplicar às pessoas submetidas ao trabalho forçado ou obrigatório nas mesmas condições dos trabalhadores livres.

A própria ONU também dispõe expressamente sobre tal questão:

A Declaração Universal dos Direitos Humanos da ONU, em seu art. 23.2, dispõe que "toda pessoa, sem qualquer distinção, tem direito a igual remuneração por igual trabalho". A LEP, por sua vez, em seu art. 29, prevê a possibilidade de remuneração inferior ao salário mínimo, garantia constitucional, para o trabalhador preso (MATOS, 2017, p. 5). 
A respeito do tema, Juarez Cirino dos Santos alerta:

Sistemas de trabalho carcerário que submetam a força de trabaIho encarcerada a qualquer outra autoridade diferente do Estado - como, por exemplo, o empresário privado - representam violação inconstitucional da dignidade da pessoa humana (art. $1^{\circ}$, $\mathrm{CF}$ ), por uma razão elementar: a força de trabalho encarcerada não tem o direito de rescindir o contrato de trabalho, ou seja, não possui a única liberdade real do trabalhador na relação de emprego e, por isso, a compulsória subordinação de seres humanos a empresários privados não representa, apenas, simples dominação do homem pelo homem, mas a própria institucionalização do trabalho escravo. Se o programa de retribuição e de prevenção do crime é definido pelo Estado na aplicação da pena criminal pelo poder Judiciário (art. 59, CP), então a realização desse programa político-criminal pelo poder Executivo através da execução da pena, vinculada ao objetivo de harmônica integração social do condenado (art. $1^{\circ}$, LEP), constitui dever indelegável do Poder Público, com exclusão de toda e qualquer forma de privatização da execução penal (SANTOS, 2013, p. 258).

A defesa neoliberal de privatização dos presídios e a obrigatoriedade de trabalho dos presos parecem ignorar que os direitos sociais são constitucionalmente protegidos e possuem força normativa e vinculante. Seu escopo gira em torno da garantia e proteção do Estado, de modo a assegurar o mínimo existencial aos cidadãos brasileiros. Como corolário, tem-se o princípio da dignidade da pessoa humana, norteador de todo o sistema jurídico brasileiro. Tudo isso é válido para todos os trabalhadores, sejam eles livres ou reclusos, uma vez que a diferenciação entre tipos laborais é expressamente proibida por nossa Carta Magna, conforme demonstrado. Nesse sentido, leciona Dirley da Cunha Júnior:

Os direitos sociais são aquelas posições jurídicas que credenciam o indivíduo a exigir do Estado uma postura ativa, no sentido de que este se coloque à disposição daquele, prestações de natureza jurídica ou material, consideradas necessárias para implementar as condições fáticas que permitam o efetivo exercício das liberdades 
fundamentais e que possibilitam realizar a igualização de situações sociais desiguais, proporcionando melhores condições de vida aos desprovidos de recursos materiais (JÚNIOR, 2009, p. 716-718).

Por conseguinte, o direito do trabalho, instrumento de luta pela justiça social, assegurado constitucionalmente, deve ser o âmago de todo labor humano na sociedade, independentemente de distinções subjetivas. As normas protetivas do trabalho e a normatização de seus princípios fundamentais possibilitam a interpretação infra nesses termos.

Nessa linha, afirma-se que o trabalho prisional, atualmente, constitui modalidade moderna de escravização temporária, incompatível com o Estado Democrático de Direito. Partindo desse pressuposto, faz-se necessário que a legislação presidiaria regule a temática com respeito máximo à igualdade, dentro dos limites que a privação de liberdade impõe. No mais, exige-se que seja cumprida, de fato, a função de ressocialização da pena. Esta apenas pode ser efetivada se existirem condições que se assemelham à sociedade livre. Do contrário, a prisão apenas servirá para dessocializar ainda mais aqueles e aquelas sob a custódia do Estado.

Em suma, é possível concluir que a exploração da mão de obra do preso da forma como é realizada hoje (e como se deseja com a ampliação da privatização prisional irrestrita) caracteriza a exploração de mão de obra barata, marginalizada e vulnerável. Tal atitude se configura como deveras desumana. Dessa maneira, resta evidente a inconstitucionalidade dos dispositivos que obrigam o preso ao trabalho, bem como os que não reconhecem os direitos decorrentes da Consolidação das Leis Trabalhistas (CLT). O que se busca, com tais violações, é impedir o reconhecimento da latente relação de emprego aos trabaIhadores encarcerados, visando apenas à aferição de lucro ligada à agressiva exploração mercantil. Esta, por sua vez, é completamente incompatível com o sistema constitucional pátrio.

\section{CONCLUSÃO}

A presente pesquisa visou a analisar o trabalho prisional como fator de mercantilização da pobreza no Estado Brasileiro, tecendo profun- 
das críticas. Porém, preocupou-se em abordar tal questão reflexa na materialidade social, isto é, propondo investida específica naquilo que possa refletir em benefícios imediatos para a sociedade, mesmo que de modo institucionalizado.

Para atingir o objetivo proposto pretendeu-se abordar três aspectos principais. Inicialmente, traçou-se as definições da categoria pashukaniana, contextualizando-a no papel de explorar a classe trabalhadora encarcerada brasileira, contribuindo para o encarceramento em massa e a criminalização da pobreza, bem como da mercantilização do crime. Para tanto, demonstrou-se que a população prisional é composta pela população negra, assumindo uma contradição suplementar do modo de produção capitalista em vistas à particularidade brasileira.

Em seguida, abordou-se a contradição presente na legalidade e ilegalidade do trabalho destes sujeitos. Tendo em vista que nos parâmetros constitucionais brasileiros tal exploração é inconstitucional. Além disso, o não reconhecimento legal da relação de emprego nos moldes celetistas também constitui afronta direta ao princípio da igualdade jurídica. Há, aqui, inerente aos parâmetros de legalidade e ilegalidade a determinação do direito como um direito burguês que se baseia em certas proibições somente para permitir a reprodução do capital.

Por último, associou-se o processo mercantilização do crime, em particular no que tange à população jovem e negra que são os de fato aprisionados, sustentada por uma cultura punitivista, à condição de precariedade, intensificada, atualmente, nos retrocessos na privatização prisional.

Assim, em um primeiro momento, buscou-se entrelaçar a análise com os aportes críticos à luz da teoria pachukaniana sobre o Direito. A partir desse ponto, partiu-se para análise da essencialidade da forma jurídica para a manutenção da forma mercadoria no modo de produção capitalista. Logo após, o enfoque foi direcionado ao investigar do conteúdo de tal forma jurídica.

Em seguida, defendeu-se as garantias fornecidas pelo Direito positivo. Contudo, importa ressaltar que a defesa de tais garantias não vai em desencontro da teoria de Pachukanis. Em verdade, a crítica 
marxista deve se debruçar sobre uma análise de enfrentamento à forma, e é preciso encarar que as garantias fazem parte do conteúdo dessa forma. A manutenção do Estado Democrático de Direito é também a preservação de milhares de excluídos e excluídas. Por todas as razões apresentadas, essa garantia deve ser feita, mas observando no seu horizonte à crítica da sua própria forma jurídica burguesa e capitalista.

\section{BIBLIOGRAFIA}

ALTHUSSER, Louis. Ideologia e aparelhos ideológicos de Estado . In: ZIZEK, Slavoj. Um mapa da ideologia. Rio de Janeiro: Contraponto, pp. 105-142.

BATISTA, Flávio Roberto. Crítica da tecnologia dos direitos sociais. São Paulo: Outras Expressões/Dobra editorial, 2013.

COUTINHO, Aldacy Rachid. Trabalho e pena. Revista da Faculdade de Direito da UFPR, Curitiba, v. 32, p. 7-23, 1999.

ELDEMAN, Bernard. A legalização da classe operária. São Paulo: Boitempo, 2016.

FILHO, José dos Santos Carvalho. Manual de direito administrativo. São Paulo: Atlas, 2013.

JÚNIOR, Dirley da Cunha. Curso de Direito Constitucional. 9a ed. Salvador: JusPODIVIM, 2009.

MATOS, Erica do Amaral. Privatização de Presídios e a Mercantilização do Crime e da Pobreza. Revista Brasileira de Ciências Criminais, São Paulo, v. 133, 2017.

MINHOTO, Laurindo Dias. Privatização de presídios e criminalidade: a gestão da violência no capitalismo global. São Paulo: Max Limonad, 2000.

MINHOTO, Laurindo Dias. Regressão nova, velha barbárie. Boletim IBCCRIM, São Paulo, v. 202, 2009. 
NICOLI, Pedro Augusto Gravatá. Trabalho encarcerado e privatização dos presídios: reflexões à luz da Convenção 29 da OIT. Direito UNIFACS, v. 111, 2009.

PACHUKANIS, Evgeni. A teoria geral do direito e o marxismo e ensaios escolhidos (1921-1929). São Paulo: Sundermann, 2017.

Recebido em 18/11/2019 Aprovado em 24/01/2020 